\title{
The CRL4 ${ }^{\text {Cdt2 }}$ ubiquitin ligase targets the degradation of $21^{\text {Cip1 }}$ to control replication licensing
}

\author{
Youngjo Kim, ${ }^{1}$ Natalia G. Starostina, and Edward T. Kipreos ${ }^{2}$ \\ Department of Cellular Biology, University of Georgia, Athens, Georgia 30602 USA
}

\begin{abstract}
The faithful replication of genomic DNA is crucial for maintaining genome stability. In eukaryotes, DNA rereplication is prevented by the temporal regulation of replication licensing. Replication-licensing factors are required to form prereplicative complexes during $\mathrm{G} 1$ phase, but are inactivated in $S$ phase to prevent rereplication. A vertebrate CUL4 CRL ubiquitin ligase (CRL4) complex containing Cdt2 as the substrate recognition subunit promotes proper DNA replication, in part, by degrading the replication-licensing factor Cdt1 during $S$ phase. We show that the Caenorhabditis elegans CRL4 ${ }^{\text {Cdt2 }}$ complex has a conserved role in degrading Cdt1. Furthermore, we show that CRL4 ${ }^{\mathrm{Cdt} 2}$ restrains replication licensing in both C. elegans and humans by targeting the degradation of the cyclin-dependent kinase (CDK) inhibitors CKI-1 and p21 ${ }^{\text {Cip1 }}$, respectively. Human CRL4 ${ }^{\text {Cdt2 }}$ targets the degradation of 221 in $S$ phase, with the in vivo ubiquitylation of p21 by CRL4 ${ }^{\text {Cdt2 }}$ dependent on p21 binding to PCNA. Inactivation of Cdt2 induces rereplication, which requires the presence of the CDK inhibitor p21. Strikingly, coinactivation of CRL4 ${ }^{\mathrm{Cdt} 2}$ and $\mathrm{SCF}^{\text {Skp2 }}$ (which redundantly targets 221 degradation) prevents the nuclear export of the replication-licensing factor Cde6 during $S$ phase, and the block on nuclear export is dependent on p21. Our work defines the degradation of p21 as a critical aspect of replication licensing in human cells.
\end{abstract}

[Keywords: CDK inhibitors; CUL4; DNA rereplication; p21; replication licensing]

Received June 9, 2008; revised version accepted August 1, 2008.

To maintain genome integrity, DNA replication must be tightly regulated so that replication only initiates once at each replication origin during $S$ phase. The cellular pathway for preventing overreplication of genomic DNA /rereplication) is focused on blocking the reformation of prereplicative complexes (pre-RCs) in S phase (Arias and Walter 2007). The pre-RC consists of the six-member origin recognition complex (ORC), the replication-licensing factors Cdt1 and Cdc6, and the DNA helicase MCM2-7 complex. Pre-RC assembly occurs prior to $S$ phase, either in late mitosis or G1 phase. The ORC binds to replication origins and recruits Cdt1 and Cdc6, which together recruit the putative replicative helicase, the MCM2-7 complex, to form the pre-RC. The formation of the pre-RC is said to provide the "license" for subsequent DNA replication. During S phase, specific pre-RC components are inactivated by various mechanisms (e.g., degradation, nuclear export, phosphorylation, or binding to inhibitors) so that pre-RCs cannot reform at replica-

${ }^{1}$ Present address: Department of Embryology, Carnegie Institution of Washington and Howard Hughes Medical Institute, Baltimore, MD 21218 USA.

${ }^{2}$ Corresponding author.

E-MAIL ekipreos@cb.uga.edu; FAX (706) 542-4271.

Article is online at http://www.genesdev.org/cgi/doi/10.1101/gad.1703708. tion origins that have already initiated DNA replication (Arias and Walter 2007).

In budding yeast, fission yeast, and Caenorhabditis elegans, multiple pre-RC components are regulated to redundantly prevent origin refiring during $S$ phase (Arias and Walter 2007; Kim and Kipreos 2008). In vertebrates, three mechanisms have been implicated in preventing DNA rereplication: the degradation of the ORC component ORC1, the nuclear export of Cdc6, and the inactivation of Cdt1 either by degradation or by binding to the Cdt1 inhibitor geminin. The degradation of ORC1 may not be a consistent regulatory mechanism, as it is observed in some mammalian cells but not in others (Arias and Walter 2007). The importance of vertebrate Cdc6 nuclear export is not well established due to the observation that a substantial fraction of endogenous Cdc6 remains nuclear-localized throughout $S$ phase (Kim and Kipreos 2008). In contrast, Cdt1 inactivation has been functionally linked to the prevention of DNA rereplication. In Xenopus and humans, limited rereplication is observed upon overexpression of a nondegradable Cdt1 mutant protein or inactivation of the Cdt1 inhibitor geminin (Vaziri et al. 2003; Melixetian et al. 2004; Zhu et al. 2004; Arias and Walter 2005; Li and Blow 2005; Yoshida et al. 2005). In C. elegans, Xenopus, humans, and fission yeast, $\mathrm{Cdt} 1$ is targeted for degradation during 
S phase by a cullin RING ubiquitin ligase (E3) complex (CRL) containing the cullin CUL4. In humans, Cdt 1 is also redundantly degraded by the $\mathrm{SCF}^{\mathrm{Skp} 2} \mathrm{E} 3$ complex (Kim and Kipreos 2007a).

In C. elegans, the inactivation of the cul-4 gene produces massive levels of DNA rereplication in proliferating cells, with DNA contents up to 100C (Zhong et al. 2003). C. elegans CUL-4 is required for both the degradation of CDT-1 and the nuclear export of CDC-6 during S phase (Zhong et al. 2003; Kim et al. 2007). CUL-4 promotes CDC-6 nuclear export by negatively regulating the level of the Cip/Kip family cyclin-dependent kinase (CDK) inhibitor CKI-1 (Kim et al. 2007). The deregulation of both CDT-1 and CDC-6 in C. elegans induces DNA rereplication (Kim et al. 2007). C. elegans CUL-4 is therefore a master regulator that negatively regulates both replication-licensing factors to prevent rereplication.

The structure of the CUL4 CRL complex (CRL4) is similar to that of other CRL complexes, and contains a RING H2 protein (Rbxl/Rocl), an adaptor protein (DDB1), and a substrate recognition subunit (SRS) (Higa and Zhang 2007; Lee and Zhou 2007; Bosu and Kipreos 2008). Rbxl binds to the $\mathrm{C}$ terminus of cullins and promotes the binding of the ubiquitin-conjugating enzyme (E2) (Bosu and Kipreos 2008). DDB1 contains three $\beta$ propeller domains and binds to the $\mathrm{N}$ terminus of CUL4 (Angers et al. 2006). The SRS links to the complex through interaction with DDB1, and recruits substrates.

Recent proteomic approaches have identified a family of WD repeat proteins containing a conserved "WDXR" motif as potential SRSs for CRL4 complexes (Angers et al. 2006; He et al. 2006; Higa et al. 2006b; Jin et al. 2006). The WDXR protein family is predicted to contain $\sim 90$ members in mammals, of which at least 50 have been shown to be capable of physical association with CUL4 or DDB1 (Angers et al. 2006; He et al. 2006; Higa et al. 2006b; Jin et al. 2006). WDXR family members include the known CRL4 complex SRSs, suggesting that a majority of the WDXR family proteins will function as SRSs. In fission yeast and vertebrates, the WDXR protein Cdt2/DTL (Cdc10-dependent transcript 2/Denticleless) functions as a CRL4 SRS to target Cdt1 for degradation (Higa et al. 2006a; Jin et al. 2006; Ralph et al. 2006; Sansam et al. 2006). The degradation of Cdt1 is dependent on its interaction with PCNA /proliferating cell nuclear antigen), which is mediated by the PCNA-binding PIP-box motif of Cdt1 (Arias and Walter 2007).

In this work, we show that the $C$. elegans Cdt2 ortho$\log$, CDT-2, functions in a CRL4 ${ }^{\text {CDT-2 }}$ complex to target the degradation of the replication-licensing factor CDT-1 and the CDK inhibitor CKI-1. We extend this to show that the human CRL4 ${ }^{\mathrm{Cdt} 2}$ complex targets the degradation of the Cip/Kip family CDK inhibitor p21 $1^{\text {Cip } 1 / \text { Waf1/Sdi1 }}$. The CRL4 ${ }^{\text {Cdt2 }}$-mediated ubiquitylation of $\mathrm{p} 21$ requires $\mathrm{p} 21$ binding to PCNA. We present evidence that CRL4 ${ }^{\mathrm{Cdt} 2}$ targets the degradation of $\mathrm{p} 21$ during $S$ phase to control the nuclear export of the Cdc6 replication-licensing factor and prevent DNA rereplication.

\section{Results}

$C R L 4^{C D T-2}$ is required for CKI-1 degradation in C. elegans

In C. elegans, cul-4 inactivation causes substantial rereplication in mitotically proliferating larval cells (Zhong et al. 2003). The rereplication in cul-4 mutants arises from a failure to negatively regulate the levels of the replication-licensing factor CDT-1 and the CDK inhibitor CKI-1 (Zhong et al. 2003; Kim and Kipreos 2007b; Kim et al. 2007). CKI-1 accumulates in rereplicating cul-4 mutant cells, and cki-1 RNAi depletion suppresses the rereplication, indicating that CKI-1 is essential for the rereplication to occur (Kim and Kipreos 2007b; Kim et al. 2007). In order to determine which SRS is responsible for the degradation of CKI-1 in C. elegans, we took a candidate gene approach. Fifty WDXR motif proteins have been identified as physical interactors with CRL4 components in mammals, and are therefore potential SRSs (Angers et al. 2006; He et al. 2006; Higa et al. 2006b; Jin et al. 2006). We identified 24 orthologs of these genes in C. elegans, and tested RNAi depletions of eight of the genes to determine if the RNAi would induce CKI-1 accumulation, as determined by immunofluorescence with anti-CKI-1 antibody. Of the tested WDXR motif genes, only the RNAi inactivation of the $c d t$-2 gene (the ortholog of mammalian CDT2) produced an accumulation of CKI-1 in larval blast cells (Fig. 1A; see the Materials and Methods section for the genes tested).

$c d t$-2(RNAi) larvae exhibit enlarged blast cells, including seam cells, that have increased DNA content, similar to what is observed in cul-4 or $d d b-1$ RNAi animals (Fig. 1A,B). The level of genomic DNA in the enlarged $c d t$ 2(RNAi) cells is $14.8 \pm 7.1$ C DNA content for L4stage larvae ( $2 \mathrm{~d}$ post-hatch), relative to $2.0 \pm 0.2 \mathrm{C}$ for wild-type L4-stage larvae, and $25.9 \pm 15.4 \mathrm{C}$ for $d d b$ 1(RNAi) arrested L2-stage larvae (3 d post-hatch). However, $c d t-2(R N A i)$ larvae do not exhibit all of the cul-4 mutant phenotypes. Unlike cul-4 or $d d b-1$ mutants, $c d t$ 2(RNAi) animals do not arrest at the L2 larval stage or exhibit a stereotypical degenerating germ cell phenotype. The observation of only a subset of cul-4 mutant phenotypes is consistent with the loss of a single class of CRL4 complex (as each class is defined by its associated SRS).

In vertebrates, Cdt2 functions as the CRL4 SRS to target the degradation of Cdt1 in S phase (Higa et al. 2006a; Jin et al. 2006; Sansam et al. 2006). We found that $C$. elegans CDT-2 is similarly required for CDT-1 degradation in $S$ phase, with CDT-1::GFP perduring in S-phase $c d t$-2(RNAi) seam cells (Fig. 1C). In cul-4 mutants, the rereplication phenotype arises from the failure to degrade CDT-1 and CKI-1 (Zhong et al. 2003; Kim and Kipreos 2007b). The observation that $c d t-2(R N A i)$ blast cells have increased DNA content and accumulate both CDT-1 and CKI-1, strongly suggests that CDT-2 functions in the context of a CRL4 complex to prevent DNA rereplication. 
A
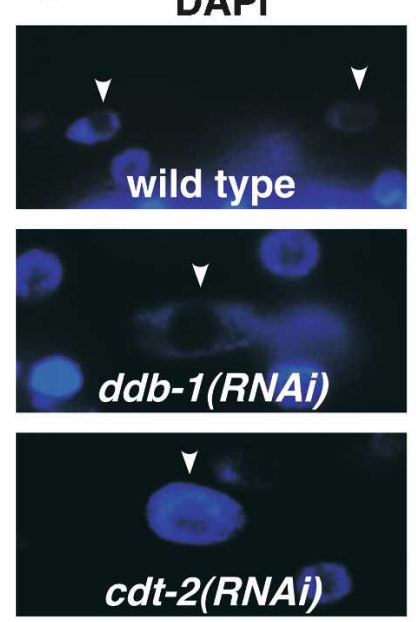

B

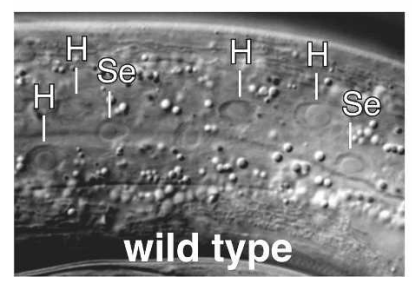

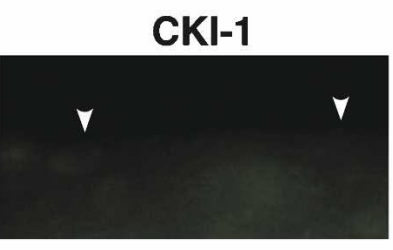
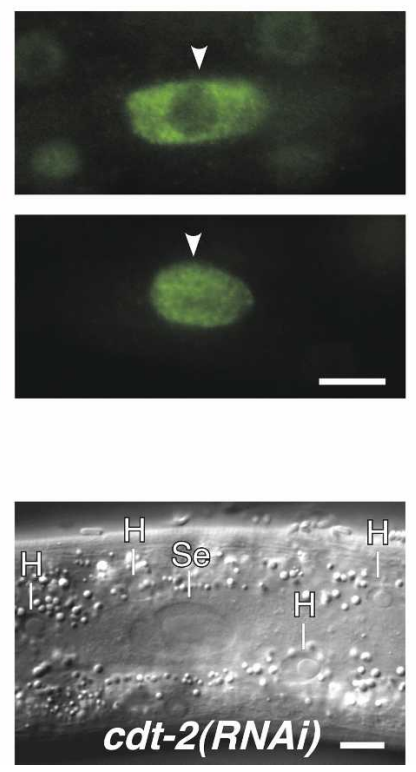

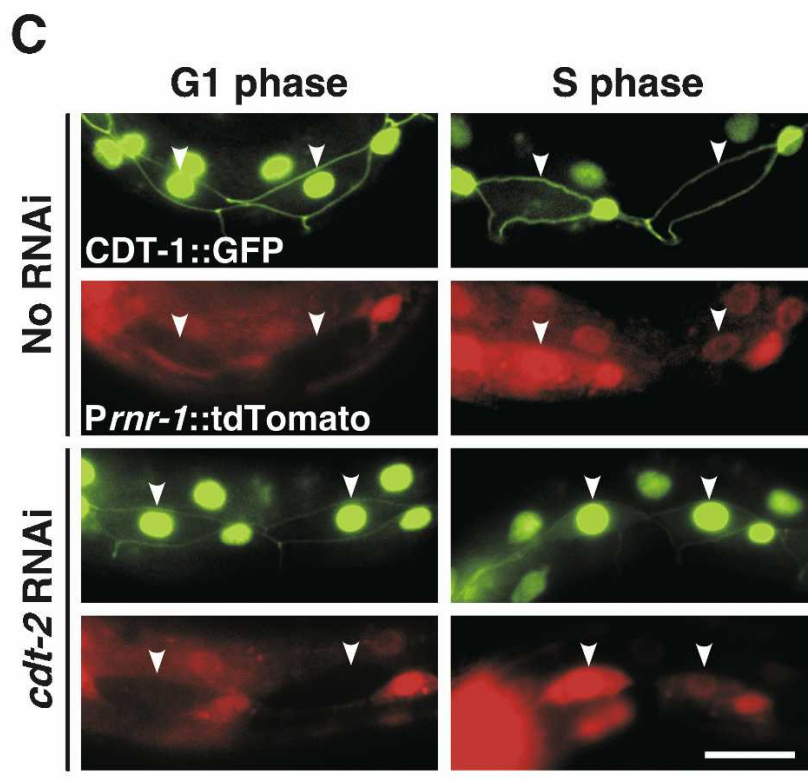

Figure 1. Loss of CDT-2 is associated with enlarged blast cells with excessive CKI-1. (A) Seam cell nuclei of wild-type, $d d b-1(R N A i)$ and $c d t$-2(RNAi) L4-stage larvae, stained with DAPI (blue) and anti-CKI-1 (green). (B) DIC images of the lateral hypodermis of L4-stage $c d t-2(R N A i)$ and wild-type larvae. Se, seam cell nuclei; $\mathrm{H}$, hyp7 cell nuclei. $(C)$ CDT-1::GFP protein expression in G1-phase and S-phase seam cells with or without $c d t-2$ RNAi treatment. Epifluorescence images show CDT-1::GFP (green) and Prnr-1::tdTomato (an S-phase marker, red). G1-phase seam cells are from larvae 90 min post-hatching, and S-phase seam cells are from larvae 210 min post-hatching. CDT-1::GFP was expressed from the seam cell-specific wrt-2 promoter (Aspock et al. 1999). Note that CDT-1::GFP is absent in S-phase wild-type cells but is present in S-phase cdt-2(RNAi) cells. Seam cell boundaries are marked by AJM-1::GFP. Arrowheads indicate seam cell nuclei. Bars, $10 \mu \mathrm{m}$.

\section{CDT-2 functions as a CRL4 complex SRS to target CKI-1 degradation}

To test if CDT-2 functions as an SRS, we analyzed the physical interactions of CDT-2 with CRL4 components and the putative substrates CDT-1 and CKI-1 using the yeast two-hybrid assay. The two-hybrid results are consistent with CDT-2 functioning as an SRS: CDT-2 interacted with the adaptor DDB-1 and with the substrates CKI-1 and CDT-1, but did not interact directly with CUL-4 (Fig. 2A [top panel], B). Also consistent with the CRL structure, the adaptor DDB-1 did not interact directly with the substrates CKI-1 or CDT-1 in the twohybrid assay (Fig. 2A, top; data not shown). We tested whether CDT-2 can act as a bridge between DDB- 1 and CKI-1 using the yeast three-hybrid test (Licitra and Liu 1996). CDT-2 was expressed from the GAL1 promoter, which is induced by galactose and repressed by glucose (Giniger et al. 1985). Yeast containing the GAL1 promoter/CDT-2 construct plus a DDB-1/GAL4 DNA-binding domain fusion and CKI-1/GAL4 activation domain fusion were able to grow on histidine(-) selection plates containing galactose but not glucose, indicating that CDT-2 can bridge interaction between DDB-1 and CKI- 1
(Fig. 2A, bottom). A similar experiment showed that DDB-1 can mediate interaction between CUL-4 and CDT-2 (Fig. 2A, bottom).

To test if CKI-1 is a ubiquitylation substrate of CDT-2, we utilized a mammalian expression system. We observed that C. elegans CDT-2 can interact with TAPtagged human DDB1, suggesting that it can interact with human CRL4 components (Fig. 2C). Coexpression of $C$. elegans CDT-2 with CKI-1 in HeLa cells stimulated the in vivo ubiquitylation of CKI-1, suggesting that CKI-1 is a direct substrate of the CRL4 ${ }^{\text {CDT-2 }}$ E3 complex (Fig. 2D). Overall, our data indicate that CDT-2 functions as a CRL4 SRS to catalyze the ubiquitin-mediated degradation of the replication-licensing factor CDT-1 and the Cip/Kip family CDK inhibitor CKI-1 in C. elegans.

\section{Human CRL4 $4^{\text {Cdt2 }}$ targets $21^{\text {Cip1 }}$ for degradation}

The mammalian Cip/Kip family includes three members $\left(\mathrm{p} 21^{\text {Cip } 1}, \mathrm{p} 27^{\mathrm{Kip} 1}\right.$, and $\left.\mathrm{p} 57^{\mathrm{Kip} 2}\right)$ that are each capable of inhibiting a wide-range of CDK holoenzymes (complexes of CDKs and cyclins) (Besson et al. 2008). To test if Cdt2 negatively regulates the levels of Cip/Kip family CDK 
A

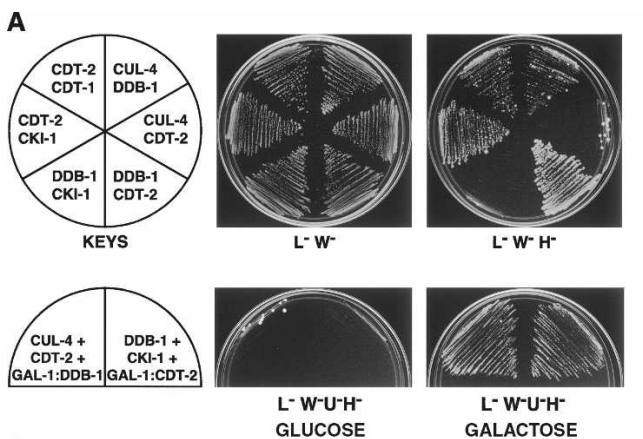

B

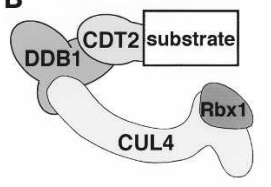

C

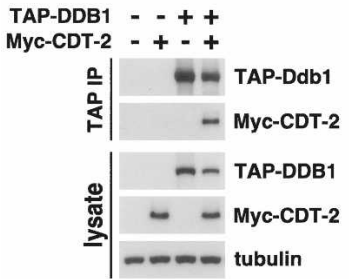

D
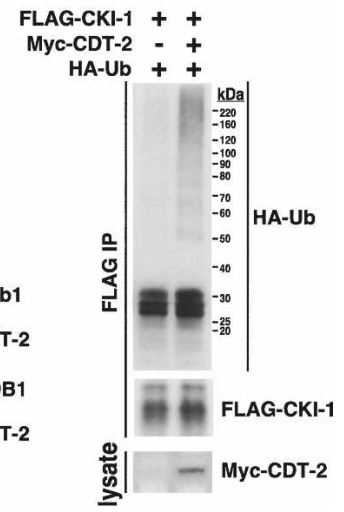

Figure 2. CDT-2 interacts with the CRL4 adaptor DDB-1 and the substrates CDT-1 and CKI-1. (A) Yeast two-hybrid (top panel) and three-hybrid (bottom panel) analysis to examine the interactions between CRL4 complex components and substrates. Note that CDT-2 binds to the putative substrates CDT- 1 and CKI- 1 and to the adaptor DDB-1 in the two-hybrid assay, but not to CUL-4. For the three-hybrid assay, DDB-1 and CDT-2 were expressed under control of the galactose-inducible GAL1 promoter. Note that CUL-4 can interact with CDT-2 only in the presence of DDB-1, and that DDB-1 can interact with CKI-1 only in the presence of CDT-2 (left and right sides of the plate, respectively). The first protein listed was expressed as a fusion with the GAL4 DNA-binding domain, and the second protein was expressed as a fusion with the GAL4 activation domain. (B) Diagram of the predicted CRL4 ${ }^{\mathrm{CDT}-2}$ structure with bound substrate. Components are labeled. $(C)$ C. elegans CDT-2 can physically associate with human TAP-DDB1 when coexpressed in $293 \mathrm{~T}$ cells. Note that pulldown of TAP-DDB1 coprecipitates C. elegans CDT-2. (D) The in vivo ubiquitylation of C. elegans CKI-1 expressed in HeLa cells is stimulated by $C$. elegans CDT-2. Flag-CKI-1 and HA-ubiquitin were coexpressed with or without Myc-CDT-2. Flag-CKI-1 was immunoprecipitated under denaturing conditions $(0.1 \%$ of SDS), and analyzed by Western blot with anti-HA and anti-Flag antibodies. Wholecell lysate was blotted to assess Myc-CDT-2 expression.

inhibitors in human cells, we determined whether Cdt2 siRNA knockdown would lead to increases in the protein levels of the three mammalian CDK inhibitors. We observed that Cdt 2 knockdown in HeLa cells produced a 5.6-fold increase in $\mathrm{p} 21^{\mathrm{Cip} 1}$ protein levels (Fig. 3A). In contrast, Cdt2 knockdown did not increase the levels of the Cip/Kip family members $\mathrm{p} 27^{\mathrm{Kip} 1}$ or p5 ${ }^{\mathrm{Kip} 2}$ (Fig. 3A). It has been reported that the $\mathrm{E} 3 \mathrm{SCF}^{\mathrm{Skp} 2}$ can target $\mathrm{p} 21$, p27, and p57 for degradation (Yu et al. 1998; Carrano et

al. 1999; Sutterluty et al. 1999; Tsvetkov et al. 1999; Bornstein et al. 2003; Kamura et al. 2003). In our experiments, Skp2 knockdown in HeLa cells increased the levels of p21 and p27, but did not affect p57 levels. Notably, coknockdown of Cdt2 and Skp2 increased p21 levels approximately twofold higher than either single knockdown (an 11-fold increase), indicating that Cdt2 and Skp2 redundantly regulate p21 (Fig. 3A). Unless otherwise noted, siRNA experiments were performed with pools of four siRNAs. Knockdowns with individual siRNAs for Cdt2 and Skp2 also produced increased p21 levels (Fig. 3B).

To determine if $\mathrm{Cdt} 2$ regulates $\mathrm{p} 21$ levels in $\mathrm{S}$ phase, we inactivated Cdt 2 in asynchronous cells and in cells enriched in S phase by hydroxyurea (HU) treatment. The level of p21 was significantly increased in S-phase Cdt2 siRNA cells relative to asynchronous Cdt2 siRNA cells, suggesting that CRL4 ${ }^{\mathrm{Cdt} 2}$ predominantly regulates $\mathrm{p} 21$ levels during $S$ phase (Fig. $3 \mathrm{C}$ ). A similar increase in $\mathrm{p} 21$ levels was also observed in aphidicolin-blocked Cdt2 siRNA cells (data not shown). In contrast to the Cdt2 knockdown, Skp2 siRNA treatment produced similar elevated levels of p21 in asynchronous and HU-treated cells, suggesting that $\mathrm{SCF}^{\mathrm{Skp} 2}$-mediated p21 degradation is not restricted to $S$ phase (Fig. 3C). To determine if Cdt 2 affects the rate of $\mathrm{p} 21$ protein turnover, we performed a time-course experiment in which Cdt2 knockdown or control GFP knockdown cells were arrested in S phase with HU in the presence of the proteasome inhibitor MG132. At time 0, HU and MG132 were removed while cycloheximide was added to block protein synthesis. We found that the half-life of endogenous p21 was significantly increased in Cdt 2 knockdown cells, indicating that Cdt2 contributes to p21 turnover during S phase (Fig. 3D).

It has been observed that p21 levels decrease during $S$ phase as serum-stimulated quiescent mammalian cells progress through the cell cycle (Dulic et al. 1998; Amador et al. 2007). We asked whether Cdt2 is required for this drop in p21 protein levels. To test this, serumstarved HeLa cells were treated with either Cdt2 siRNA or control GFP siRNA, and then stimulated with serum. As previously reported, p21 levels increased in control cells after serum stimulation and then decreased as cells progressed through S phase (Fig. 3E). Cdt2 protein levels were very low in quiescent control cells, but increased significantly upon serum stimulation, with the highest level observed at $9 \mathrm{~h}$ post-serum stimulation coincident with increased expression of Cyclin B1, indicating that the cells had entered S phase (Fig. 3E). The increase in Cdt2 levels correlated with the decrease in p21 levels. In Cdt2 knockdown cells, the induction of Cdt2 protein after serum stimulation was blocked, and p21 was markedly stabilized as cells progressed through $\mathrm{S}$ phase (Fig. $3 E)$. Our results indicate that Cdt2 contributes significantly to the degradation of p21 during $S$ phase in mitotically dividing cells.

To determine if Cdt 2 directly targets the degradation of p21, we tested for physical interaction between p21 and Cdt2. We observed that when expressed in HEK293T cells, Flag-Cdt2 and Myc-p21 reciprocally coimmunopre- 

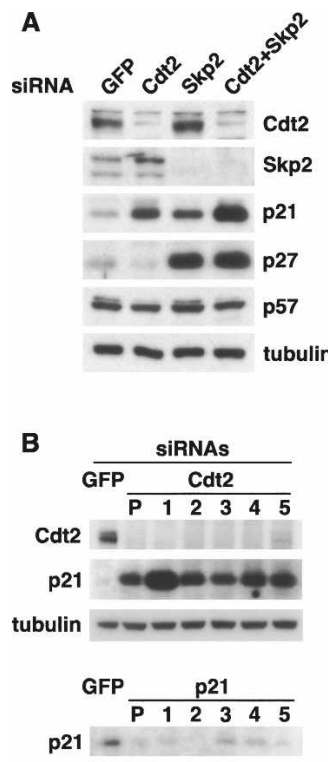

tubulin ------

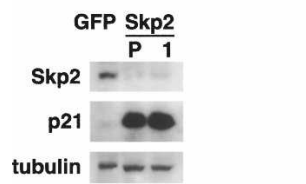

C

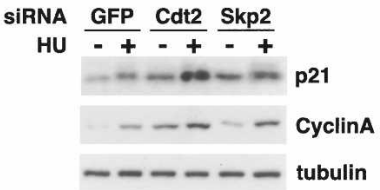

D

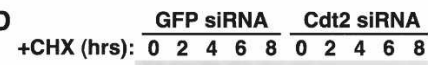

(CHX): $0 \begin{array}{lllllllll}0 & 4 & 6 & 8 & 0 & 2 & 4 & 6 & 8\end{array}$

dark exp.

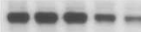

Cdt2

light exp.
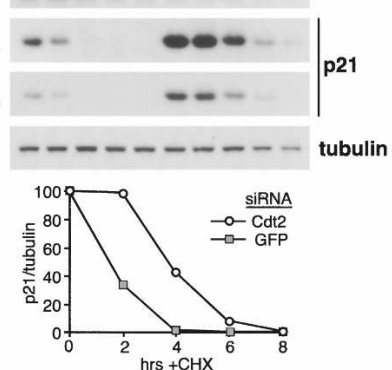

E

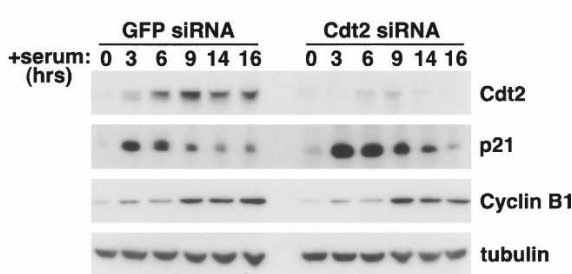

Figure 3. Cdt 2 targets $\mathrm{p} 21$ for degradation in $\mathrm{S}$ phase. $(A)$ Asynchronously growing HeLa cells were transfected with siRNA for GFP (a control), Cdt2, Skp2, or Cdt2 and Skp2 together, and the levels of the indicated proteins in the lysates were assessed by Western blot. Note that p 21 protein levels increase upon siRNA knockdown of either Cdt2 or Skp2, and are further increased upon siRNA knockdown of both Cdt2 and Skp2. (B) Comparison of siRNA knockdown of individual siRNAs (numbered) and pooled siRNAs $(\mathrm{P})$ for Cdt2, Skp2, and $\mathrm{p} 21$. The pools contain the individual siRNAs \#2-\#5. Note that knockdowns with individual siRNAs for Cdt2 and Skp2 increase p21 levels similar to the pooled siRNAs. (C) A comparison of p21 levels in asynchronous or S-phase-enriched HU-treated HeLa cells subjected to GFP, Cdt2, or Skp2 siRNA. Cyclin A is a marker of S/G2 phase, and $\alpha$-tubulin is a loading control. Note that p21 levels are higher in HU-treated than asynchronous Cdt2 siRNA cells. The increased Cyclin A protein level in asynchronous Cdt 2 siRNA cells reflects the increased number of cells in $S$ phase (undergoing rereplication with greater than 4C DNA content, see Fig. 6). (D) Analysis of p21 protein turnover in Cdt2 knockdown cells. GFP or Cdt2 siRNA-treated HeLa cells were arrested in S phase with HU and incubated with the proteasome inhibitor MG132. At time 0, HU and MG132 were removed and replaced with media containing the protein synthesis inhibitor cycloheximide (CHX). Cells were harvested at the indicated times and analyzed by Western blot. Dark and light exposures of the p21 blot are shown to facilitate a comparison of p21 turnover in GFP and Cdt2 siRNA cells. A graph of the ratio of p21 to tubulin levels is presented with values standardized to $100 \%$ at time 0 for each siRNA cell type. (E) Time course of p 21 levels in serum-stimulated Cdt2 and control knockdown cells. HeLa cells were serum starved and treated with the individual Cdt2 siRNA (\#1) or GFP siRNA. The quiescent cells were stimulated to enter the cell cycle by the addition of serum, and collected at the times indicated. Cyclin B1 is presented as a cell cycle marker whose expression begins in S phase (Pines and Hunter 1992).

cipitate with each other, while Flag-Cdt2 did not show significant interaction with Myc-p2 $7^{\text {Kip1 }}$ (Fig. 4A). We also asked whether the expression of Cdt2 would allow interaction between $\mathrm{p} 21$ and DDB1, as expected for an SRS. We observed that significantly more p21 associated with expressed TAP-tagged DDB1 in the presence of Flag-Cdt2 than in its absence (a 6.7 -fold difference) (Fig. 4B). The observed low-level of $\mathrm{p} 21$ bound to TAP-DDB1 in the absence of Flag-Cdt2 was potentially mediated by interaction with the endogenous Cdt2.

We next sought to determine if Cdt2 facilitated p21 ubiquitylation. We observed that expression of Flag-Cdt2 stimulated the in vivo conjugation of HA-ubiquitin to endogenous p21 (Fig. 5A). Expression of Flag-Skp2 also stimulated the in vivo ubiquitylation of $\mathrm{p} 21$, consistent with the siRNA data that showed that both E3 complexes regulate p21 levels (Fig. 5A). The CRL4 ${ }^{\mathrm{Cdt} 2}$ complex can catalyze the in vitro ubiquitylation of p21 (Fig. $5 \mathrm{~B})$. Taken together, our results suggest that $\mathrm{p} 21^{\mathrm{Cip} 1}$ is a direct target for ubiquitylation by the CRL4 ${ }^{\mathrm{Cdt} 2}$ E3 ligase.

\section{p21 degradation is PIP-box-dependent}

The ubiquitylation of vertebrate Cdt1 by CRL4 ${ }^{\mathrm{Cdt} 2}$ is dependent on the interaction of Cdt1 with PCNA, me- diated by the PIP-box sequence of Cdt1 (Higa et al. 2006a; Hu and Xiong 2006; Jin et al. 2006; Nishitani et al. 2006; Senga et al. 2006). p21 has a C-terminal PIP-box motif and can bind to PCNA (Waga et al. 1994). We observed that the precipitated Flag-Cdt2 immunocomplex, which was capable of in vitro ubiquitylation of Myc-p21,
A

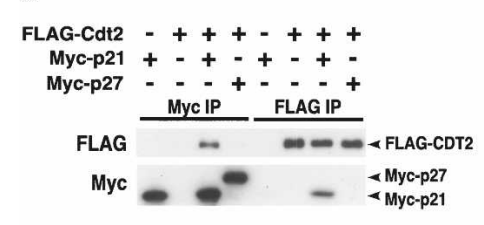

B

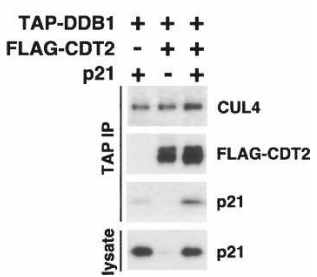

Figure 4. CRL4 ${ }^{\mathrm{Cdt} 2}$ can physically interact with $\mathrm{p} 21 .(A) \mathrm{Cdt} 2$ can bind p21. Flag-Cdt2 was coexpressed with either Myc-p21 or Myc-p27 in HEK293T cells as noted by plus symbols $(+)$ above the lanes. Anti-Flag immunoprecipitation (IP) or anti-Myc IP were analyzed by Western blot with anti-Flag antibody (top panel) or anti-Myc antibody (bottom panel). (B) DDB1 binds to p21 in a Cdt2-dependent manner. Flag-Cdt2 and nontagged p21 were expressed in HEK293T cells stably expressing TAP-DDB1 as noted above the lanes. Total protein extract and the TAPDDB1 pulldown were probed with the indicated antibodies. 
contains PCNA (Fig. 5C; data not shown). To determine the importance of the PIP-box for the physical interaction between p21 and Cdt2, we converted the PIP-box sequence of $\mathrm{p} 21$ (QTSMTDFY) to eight alanine residues. The p21 PIP-box mutant protein coprecipitated with Flag-Cdt2 at levels equivalent to that of wild-type p21 (Fig. 5D). As expected, PCNA was only coprecipitated above background levels with wild-type p21 but not the p21 PIP-box mutant, suggesting that Cdt2 can bind p21 independently of PCNA association (Fig. 5D).

To determine if the PIP-box of p21 is required for its in vivo ubiquitylation, we expressed wild-type p21 or PIPbox mutant p21 along with HA-ubiquitin and Flag-Cdt2. We observed that the in vivo ubiquitylation of wild-type p21 was significantly greater than the ubiquitylation of the p21 PIP-box mutant (Fig. 5E). This suggests that p21 ubiquitylation depends on PCNA binding, providing a mechanistic link between the CRL4 ${ }^{\mathrm{Cdt} 2}$-mediated degradation of the two substrates Cdt1 and p21, with both ubiquitylation reactions dependent on interaction with PCNA.

\section{p21 is required for the rereplication induced upon inactivation of CRL4 $4^{\text {Cdt2 }}$}

We observed that Cdt2 siRNA treatment of HeLa cells induces rereplication, producing increased numbers of cells with DNA content greater than 4C (Fig. 6), similar to what has been reported previously (Jin et al. 2006). Notably, Skp2 siRNA did not produce cells with DNA content greater than $4 \mathrm{C}$, and coinactivation of Cdt 2 and Skp2 did not increase the percentage of cells with greater than 4C DNA content beyond that of Cdt2 siRNA alone (Fig. 6). Thus, Cdt2 is required to prevent DNA rereplication in HeLa cells, while Skp2 does not significantly contribute to the prevention of overreplication. Strikingly, the rereplication observed with both Cdt2 knockdown and the coknockdown of Cdt2 and Skp2 was abolished upon coinactivation of p21 (Fig. 6). Thus, p21 is essential for the rereplication that occurs when Cdt 2 is inactivated.

\section{$C R L 4^{C d t 2}$ and $S C F^{S k p 2}$ redundantly promote Cdc6 nuclear export in a p21-dependent manner}

In C. elegans, CUL4 promotes the nuclear export of the replication-licensing factor CDC-6 by negatively regulating the levels of CKI-1, which allows CDKs to phosphorylate CDC-6 and induce its nuclear export (Kim et al. 2007). Based on our observation that CRL4 ${ }^{\text {Cdt2 }}$ targets the degradation of $\mathrm{p} 21$, we wanted to determine if the regulation of p21 levels would similarly control Cdc6 nuclear export in humans. We followed the subcellular localization of endogenous Cdc6 in HeLa cells using im-
Figure 5. $\mathrm{CRL} 44^{\mathrm{Cd} 2}$-mediated ubiquitylation of p21. (A) Overexpressing Cdt2 and Skp2 stimulates the in vivo ubiquitylation of endogenous p21 in HeLa cells. Flag-Cdt2 and Flag-Skp2 were coexpressed with HA-ubiquitin (noted at the top). Endogenous $\mathrm{p} 21$ was immunoprecipitated from whole-cell lysate under denaturing conditions $(0.1 \%$ SDS $)$, followed by anti-HA and anti-p21 immunoblotting. Note that the lysates were probed with anti-Cdt2 and anti-Skp2 antibodies to show total Cdt2 and Skp2 levels, both endogenous and overexpressed. Lane 2 shows a total Cdt2 level that is 1.7fold that of the control lane and a higher-molecularweight HA-ubiquitin signal that is 2.8 -fold that of the control lane. The level of Flag-Cdt2 and FlagSkp2 proteins in lanes 2 and 3 were suppressed relative to lane 4 by coexpression with the empty vector pEGFP-N1 (included in the first three transfections). (B) In vitro ubiquitylation of $\mathrm{p} 21$ by the CRL4 ${ }^{\mathrm{Cdt} 2}$ complex. Flag-Cdt2 and nontagged p21 were coexpressed in HEK293T cells in the presence of MG132. The CRL4 ${ }^{\text {Cdt2 }}$ complex (with associated overexpressed p21) was immunoprecipitated with anti-Flag antibody, and used in an in vitro ubiquitylation reaction. p21 was subsequently immunoprecipitated under denaturing conditions $10.1 \%$ SDS), followed by immunoblotting for HA-ubiquitin and p21. (C) Coimmunoprecipitation of PCNA withMyc-p21 in HEK293T cells. The transgenes noted were coexpressed and Flag-Cdt2 was immunoprecipitated. Western blots with antibodies to the indicated proteins were performed to assess coimmunoprecipitation. $(D)$ Both wild-type and PIP-box mutant p21 immunoprecipitate with Flag-Cdt2 from a chromatin fraction of HeLa cells. Note that PCNA efficiently coprecipitated with Flag-Cdt2 in the presence of overexpressed wild-type p21 but not PIP-box mutant p21. (E) Wild-type p21 is more efficiently ubiquitylated in vivo than PIP-box mutant p21 upon cotransfection with Flag-Cdt2 in HeLa cells. Transfected p21 was immunoprecipitated from a nuclear fraction under denaturing conditions, followed by anti-HA and anti-p21 immunoblotting. Asterisks mark nonspecific bands.
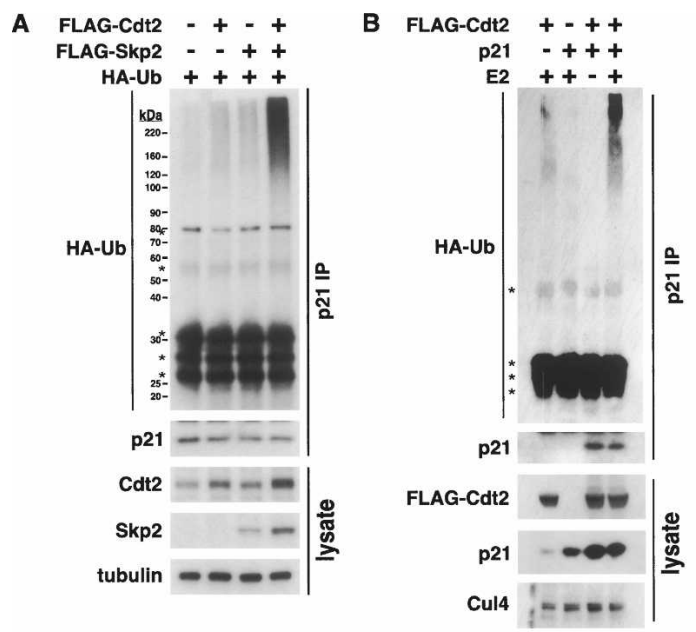

E FLAG-Cdt2 +++

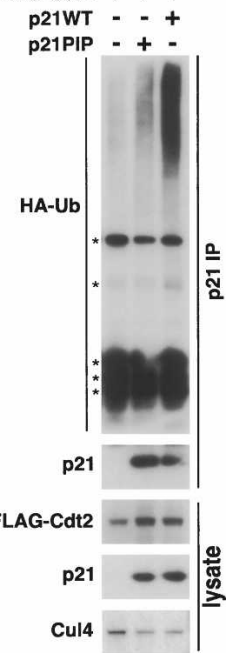

C

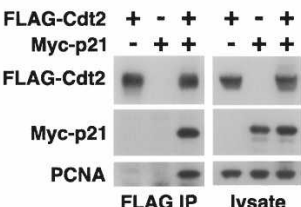

D

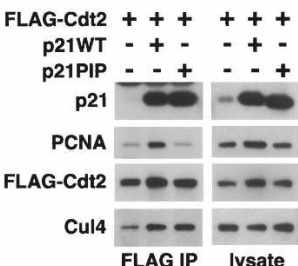




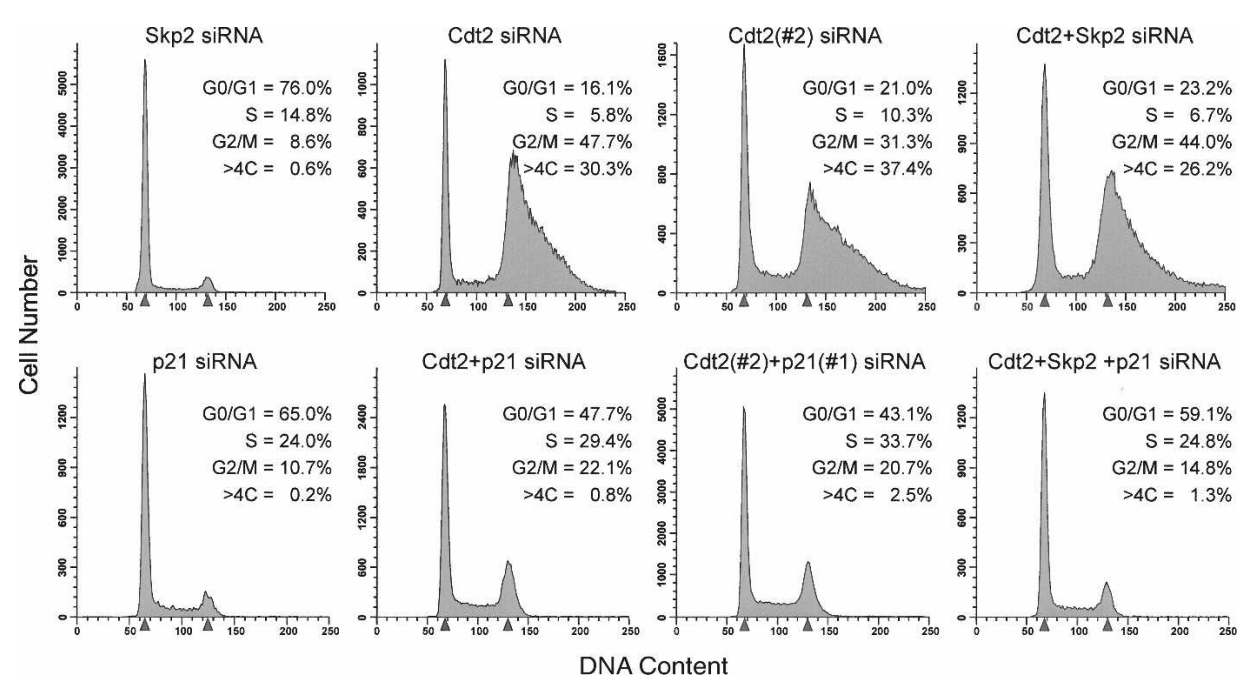

Figure 6. Cdt2 siRNA induces increased DNA content, which is reversed by p21 siRNA. Flow cytometry profiles of DNA content of HeLa cells transfected with the indicated siRNAs. Pools of four siRNA were used with the exception of the third graphs from the left, which used individual siRNAs. The increase in DNA content upon Cdt2 knockdown was observed in siRNA treatments with the Cdt2 siRNA pool and two different individual Cdt2 siRNAs that were tested (\#1 and \#2), and the block on rereplication by coinactivation of $\mathrm{p} 21$ was observed with the p21 siRNA pool and two different individual p21 siRNAs that were tested (\#1 and \#2) (above; data not shown). The percentages of cells in each cell cycle phase are provided for each graph. (G0/G1) $2 \mathrm{C}$ DNA content; (S) $2 \mathrm{C}<x<4 \mathrm{C}$; (G2/M) 4C; and >4C. Control GFP siRNA cells had a DNA distribution that was similar to that of p21 siRNA: (G0/G1) 62.4\%; (S,) $22.5 \%$; $(\mathrm{G} 2 / \mathrm{M}) 13.3 \%$; and $(>4 \mathrm{c}) 1.9 \%$. The position of $2 \mathrm{C}$ and $4 \mathrm{C}$ are noted by triangles at the bottom of each graph.

munofluorescence with anti-Cdc6 antibody. Cells were costained with anti-Cyclin A antibody to mark cells in S/G2 phase. In the control siRNA population, Cdc6 is predominantly nuclear localized in Cyclin A-negative cells (G1 phase), while Cdc6 is primarily cytoplasmic in Cyclin A-positive cells (S/G2 phase), indicating that the majority of Cdc6 is exported to the cytoplasm during $\mathrm{S}$ phase (Fig. 7A,B; data not shown). The majority of Cdt2 siRNA cells have cytoplasmic-localized Cdc6 during S/G2 phase, although an increased percentage of cells exhibit equal distributions of nuclear and cytoplasmic Cdc6. The percentage of the total cellular Cdc6 signal that is nuclear-localized upon Cdt2 knockdown is modestly higher than in control GFP knockdown cells $(31 \pm 1.8 \%$ vs. $25 \pm 1.7 \% ; P=0.05$, Student's $t$-test). Skp2 knockdown led to a greater reduction in Cdc6 nuclear export, with over half the cells showing equivalent levels of nuclear and cytoplasmic Cdc6 (Fig. 7A,B). Strikingly, when Cdt2 and Skp2 were inactivated together, a majority of Cyclin A-positive cells exhibited nuclear-localized Cdc6, indicating an almost total failure of Cdc6 nuclear export (Fig. 7A,B). Therefore, both Cdt2 and Skp2 are redundantly required to allow Cdc6 nuclear export during $S$ phase.

We hypothesized that the failure to degrade $\mathrm{p} 21$ upon inactivating both Cdt2 and Skp2 contributed to the block on Cdc6 nuclear export during $\mathrm{S}$ phase. Knockdown of p21 by itself has no effect on the subcellular distribution of Cde6 relative to control cells (data not shown). To test if p21 was required for the failure of Cdc6 nuclear export in Cdt2 and Skp2 double-knockdown cells, we coinactivated p21, Cdt2, and Skp2. Western blotting demonstrated the high efficiency of the triple siRNA knockdown (Fig. 7C). As we hypothesized, coinactivation of $\mathrm{p} 21$ with Cdt2 and Skp2 markedly increased the percentage of Cdc6 that was cytoplasmiclocalized in S/G2-phase cells, indicating that p21 is required for the block on Cdc6 nuclear export (Fig. 7A,B). We note that the p21, Cdt2, Skp2 triple-knockdown cells retain higher nuclear Cdc6 levels than Cdt2 knockdown cells even though the triple-knockdown cells do not undergo rereplication while a substantial percentage of Cdt2 knockdown cells rereplicate. This suggests that increased Cdc6 nuclear localization is not sufficient to explain how p21 contributes to rereplication, and implies that the presence of p21 in S-phase cells deregulates additional replication-licensing pathway(s).

\section{Discussion}

In this study, we identified the C. elegans WDXR motif protein CDT-2 as an SRS for a CRL4 E3 complex that targets the CDK inhibitor CKI-1 and the replication-licensing factor CDT- 1 for degradation. CDT-2 can bind to both CKI- 1 and CDT-1 and negatively regulate their protein levels in C. elegans. CDT-2 also promotes the ubiquitylation of CKI-1 when expressed in mammalian cells. We extended our findings by demonstrating that the human CRL4 ${ }^{\text {Cdt2 }}$ complex has a conserved function in targeting the degradation of the CDK inhibitor $\mathrm{p} 21^{\mathrm{Cip} 1}$. Inactivation of Cdt2 in HeLa cells causes a significant increase in p21 levels, but does not affect the levels of the related CDK inhibitors $\mathrm{p} 27^{\mathrm{Kip} 1}$ and $\mathrm{p} 57^{\mathrm{Kip} 2}$. Cdt2 overexpression stimulates the in vivo ubiquitylation of $\mathrm{p} 21$. The CRL4 ${ }^{\text {Cdt2 }}$ complex binds p 21 in vivo and can ubiq- 
Kim et al.

A
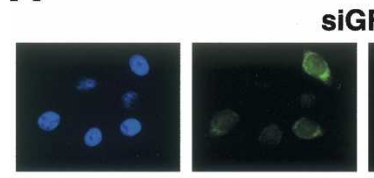

siCdt2
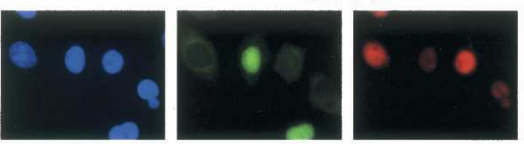

siSkp2
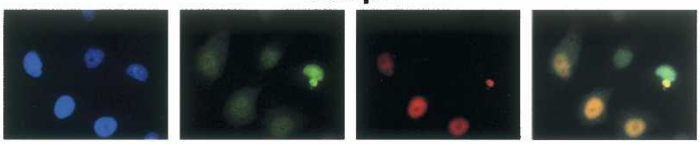

siCdt2 + siSkp2
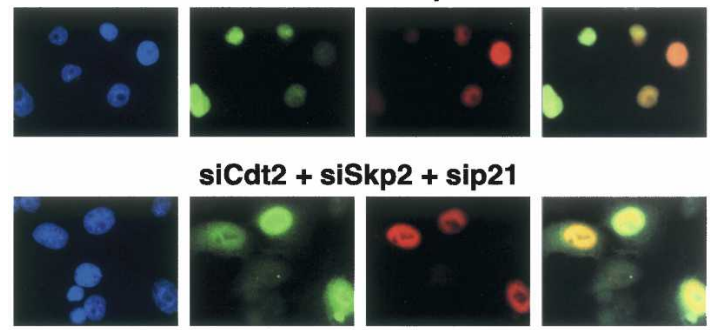

DAPI
siCdt2 + siSkp2 + sip21

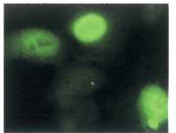

Cde6

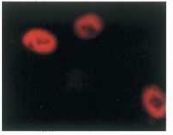

Cyclin A
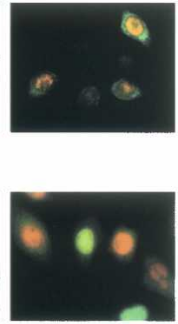

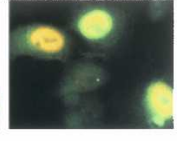

merge
B

$\% \mathbf{N} / \mathbf{T}$

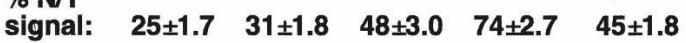

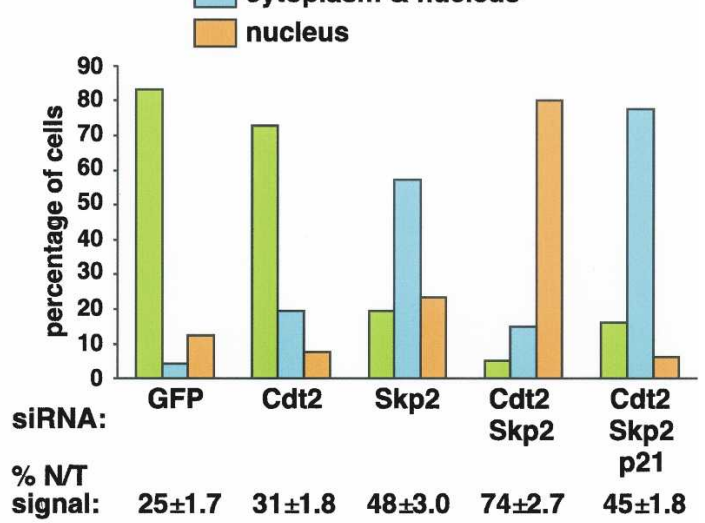

C

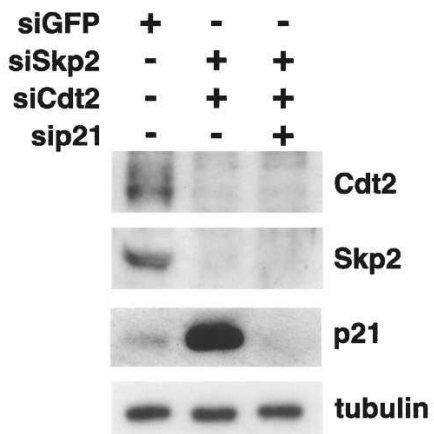

Figure 7. Cdc6 is exported from the nucleus during S phase in a p21-dependent manner. $(A)$ HeLa cells were transfected with the indicated siRNA pools and examined by immunofluorescence with anti-Cdc6 and anti-Cyclin A antibodies. Similar Cdc6 subcellular distributions were obtained with individual siRNAs for Cdt2 (\#1 and \#2), Skp2 (\#1), and p21 (\#1 and \#2) (data not shown). (B) Quantification of immunofluorescence images of Cyclin A-positive cells from the experiment in $A$. Graph bars represent the percentage of cells with predominantly cytoplasmic Cdc6 staining; equal nuclear and cytoplasmic staining; or predominantly nuclear staining. The number \pm SEM given below each condition is the percentage of total Cdc6 signal per cell that is nuclear localized within the S/G2-phase cells. $(C)$ Western blot of protein extract from double and triple siRNA cells to reveal the efficiency of siRNA knockdown.

uitylate $\mathrm{p} 21$ in vitro. Therefore, we propose that $\mathrm{p} 21^{\mathrm{Cip} 1}$ is a direct substrate of the CRL4 ${ }^{\mathrm{Cdt} 2} \mathrm{E} 3$ complex.

The CDK inhibitor $\mathrm{p} 21$ has a central role as an effector of cell cycle arrest when it is transactivated by the p53 tumor suppressor protein in response to DNA damage (Besson et al. 2008). While p21 is primarily considered an inhibitor of $\mathrm{CDK} /$ cyclin complexes, it also has CDK-independent functions involving the regulation of the cytoskeleton, transcription, and apoptosis (Besson et al. 2008). During the cell cycle, p21 levels are high in G1 phase, decrease significantly during $S$ phase, and increase again during G2 phase (Dulic et al. 1998; Amador et al. 2007). p21 has been shown to undergo proteasome-mediated degradation through the actions of a number of E3s: SCF ${ }^{\text {Skp2 }}$, MDM2, MDMX, and APC/C $\mathrm{C}^{\mathrm{Cdc} 20}$ (Yu et al. 1998; Carrano et al. 1999; Jin et al. 2003, 2008; Amador et al. 2007). APC/C $\mathrm{C}^{\mathrm{Cdc} 20}$ targets the degradation of $\mathrm{p} 21$ during prometaphase (Amador et al. 2007). MDM2 and MDMX promote the proteasomal turnover of $\mathrm{p} 21$ predominantly in G1 and early S phases (Jin et al. 2008). $\mathrm{SCF}^{\text {Skp2 }}$ has been shown to target p21 degradation in S-phase cells (Bornstein et al. 2003); however, our study suggests that this degradation is not restricted to $S$ phase. In contrast, we observed that CRL4 ${ }^{\mathrm{Cdt} 2}$-mediated degradation of p21 occurs primarily in $S$ phase.

We showed that the in vivo ubiquitylation of $\mathrm{p} 21$ by CRL4 ${ }^{\text {Cdt2 }}$ is dependent on p21 binding to PCNA. The binding of Cdt 1 to chromatin-associated PCNA has been proposed as a mechanism to ensure that Cdt1 degradation is S-phase-specific (Arias and Walter 2006; Senga et al. 2006), and a similar mechanism may explain the Sphase specificity of the CRL4 ${ }^{\mathrm{Cd} 2}$-mediated p 21 degradation. The significance of the PCNA-p21 interaction is underlined by the independent discovery that CRL4 ${ }^{\text {Cdt2 }}$ targets p21 degradation in response to DNA damage in a PCNA-dependent manner ( $T$. Abbas and A. Dutta, pers. comm.).

The observation that the CRL4 ${ }^{\mathrm{Cdt} 2}$-mediated degradation of both Cdt1 and p21 substrates is PCNA-dependent suggests that Cdt2 may have evolved to specifically target substrates in the context of PCNA binding. It is possible that CRL4 ${ }^{\mathrm{Cdt} 2}$-mediated ubiquitylation in response to PCNA binding will be a general mechanism for degrading S-phase substrates, analogous to the degradation 
of mitotic substrates by APC/C. The most obvious candidates for this regulation are the numerous identified PCNA-binding proteins (Moldovan et al. 2007). p21 has previously been shown to bind PCNA, and this interaction was suggested as a mechanism to inactivate PCNA after DNA damage (Waga et al. 1994). The PCNA-p21 interaction has recently been shown to promote the targeting of DNA repair proteins to sites of DNA damage (Cazzalini et al. 2008; Masih et al. 2008). However, the role of PCNA-p21 interaction in normal cell cycle progression had not been determined (Moldovan et al. 2007). Our results suggest that the interaction of PCNA and p21 during $\mathrm{S}$ phase promotes $\mathrm{p} 21$ degradation to allow the proper temporal regulation of DNA replication licensing.

The inactivation of Cdt2 induces rereplication in HeLa cells (Jin et al. 2006). Strikingly, we found that the rereplication induced by Cdt2 knockdown is abolished by the coinactivation of $\mathrm{p} 21$. Although both CRL4 ${ }^{\mathrm{Cdt} 2}$ and $\mathrm{SCF}^{\mathrm{Skp} 2}$ target the degradation of Cdt 1 and $\mathrm{p} 21$, there are clear differences in the relevance of the two E3 complexes for the prevention of DNA rereplication. Inactivation of Cdt2 induces substantial rereplication, while inactivation of Skp2 does not produce rereplication. It is possible either that CRL4 ${ }^{\mathrm{Cdt} 2}$ and $\mathrm{SCF}^{\mathrm{Skp} 2}$ target different subpopulations of Cdt1 and p21, or that there are additional targets of CRL4 ${ }^{\text {Cdt2 }}$ whose degradation restrains DNA replication licensing.

In C. elegans, the failure to export $\mathrm{Cdc} 6$ during $\mathrm{S}$ phase in cul-4 mutants is directly linked to the rereplication phenotype (Kim et al. 2007). In HeLa cells, inactivating either Cdt2 or Skp2 alone produces only partial effects on Cdc6 nuclear export during S phase. However, coinactivation of both Cdt2 and Skp2 produces an almost complete block on Cdc6 nuclear export, indicating that the nuclear export is redundantly controlled by the two E3 ligases. The coinactivation of p21 with Cdt2 and Skp2 partially suppresses the Cdc6 nuclear export defect, suggesting that $\mathrm{CRL} 4^{\mathrm{Cdt} 2}$ and $\mathrm{SCF}^{\text {Skp2 }}$ regulate $\mathrm{Cdc} 6$ nuclear export, at least in part, via degradation of p21.

In vertebrates, it has not been determined whether the nuclear export of Cdc6 inhibits its activity during $S$ phase because a substantial fraction of endogenous Cdc6 remains in the nucleus throughout $S$ phase (Kim and Kipreos 2008). Our results do not clarify this issue, as we observed rereplication in Cdt2 knockdown cells in which there was only a modest increase in Cdc6 nuclear retention; and so it is not clear if the limited increase in nuclear Cdc6 allowed the rereplication or whether the increase was immaterial. However, we can conclude that Cdc6 nuclear retention is not sufficient to explain how p21 promotes rereplication. This is based on the observation that while coinactivation of $\mathrm{p} 21$ with $\mathrm{Cdt} 2$ and Skp2 blocks rereplication, these triple-knockdown cells have higher nuclear Cdc6 levels than Cdt2 single-knockdown cells, which undergo rereplication. Therefore, an elevated level of nuclear Cdc6 is not sufficient to induce rereplication in the absence of $\mathrm{p} 21$ in Cdt2 and Skp2 double-knockdown cells. This implies that p21 promotes rereplication through additional pathways beyond its effect on Cdc6 localization.
The increased level of p21 in Cdt2 knockdown cells may promote rereplication either by inhibiting $\mathrm{CDK} / \mathrm{cy}$ clin activity or through CDK-independent mechanism(s). CDK/cyclin activity has been shown to inhibit the reinitiation of DNA replication during $S$ phase in a number of eukaryotes (Arias and Walter 2007; Kim and Kipreos 2008). In budding yeast, CDK/cyclins block preRC formation through at least three pathways: induction of Cdc6 degradation, inactivation of ORC components, and the nuclear export of the Mcm2-7 helicase (Nguyen et al. 2001). In mammalian cells, siRNA knockdown of both CDK1 and CDK2 induces rereplication, suggesting that CDK activity is an essential aspect of restricting replication licensing (Machida and Dutta 2007). However, the relevant mammalian CDK/cyclin targets have not been identified, but may include Cdc6, whose subcellular localization is regulated by CDK-mediated phosphorylation (Kim and Kipreos 2008). Our results imply that Cdc6 cannot be the sole relevant target of CDK/ cyclins, and that other functional CDK/cyclin targets exist, whose phosphorylation prevents rereplication. The additional mechanism(s) by which elevated $\mathrm{p} 21$ fosters rereplication are not known, but could involve promoting Cdt1 activity or more novel pathways to initiate preRC reformation.

From an evolutionary perspective, it is striking that the CRL4 ${ }^{\text {Cdt2 }}$ complex has been conserved as a master regulator of DNA replication licensing. In both nematodes and humans, CRL4 ${ }^{\text {Cdt2 }}$ controls the licensing factor Cdt1 (via degradation) and the licensing factor Cdc6 (via localization). Further, in both species, CRL4 ${ }^{\text {Cdt2 }}$ catalyzes the degradation of a CDK inhibitor in order to prevent the reinitiation of DNA replication. We propose that actively reducing CDK inhibitor activity during $S$ phase is a central mechanism among metazoa for the prevention of DNA rereplication. Our results suggest that in humans, the degradation of p21 in S-phase cells performs this role.

\section{Materials and methods}

\section{C. elegans analysis}

The strains used were as follows: N2, wild type; ET341, unc119(ed4); ekEx23[pPD95.75/Pwrt-2::CDT-1::GFP + pPD95.67/ Prnr-1::tdTomato + pRF4]; syIs78[AJM-1::GFP + unc-119(+)]. RNAi was performed using the feeding RNAi protocol as described (Kamath et al. 2001). L4-stage larvae were placed on RNAi and their progeny were analyzed. $c d t-2$ RNAi was performed with E. coli strain HT115 containing plasmid pPD129.36/cdt-2, which contains a full-length $c d t-2$ cDNA situated between double T7 promoters. RNAi depletion of the following WDXR genes were analyzed by anti-CKI-1 immunofluorescence: D2030.9, F47D12.9, F53C11.7, R11D1.1, T01C3.1 (cdt-2), Y73E7A.9, ZK430.7, and ZK1251.9. Anti-CKI-1 immunofluorescence and quantitation of DNA content were performed as described (Kim and Kipreos 2007b). The isolation of larvae at set times post-hatch for the observation of CDT$1::$ GFP in seam cells in G1 or S phase was performed as described (Zhong et al. 2003). 
Yeast two- and three-hybrid assays

For two-hybrid analysis, the full-length cul-4, ddb-1, cdt-2, cki1 , and $c d t-1$ cDNAs were cloned into the vectors pACT2 (which encodes GAL4 activation domain fusion) and pAS2 (encodes GAL4 DNA-binding domain fusion) (Clontech). Plasmids were transformed into the Saccharomyces cerevisiae strain pJ69-4A (James et al. 1996) using standard procedures (Ausubel et al. 1995). Interaction in the two-hybrid system was assayed on histidine-deficient selective media containing $1 \mathrm{mM} 3$-amino1,2,4-triazole (3-AT, Sigma). For three-hybrid tests, $c d t-2$ and $d d b-1$ cDNAs were cloned into the pYES2 vector (Invitrogen), in which the gene of interest is under the control of the GAL1 promoter. Two-hybrid bait and prey plasmids as well as the pYES2 construct were cotransformed into pJ69-4A. Interaction in the three-hybrid system was determined on histidine-deficient selective media containing $1 \mathrm{mM} 3$-AT in the presence of $2 \%$ glucose or galactose.

\section{Expression constructs}

To express Flag-tagged proteins in mammalian systems, cDNAs of human Cdt2 and C. elegans cki-1 were cloned into pCMVTag2 (Stratagene). For Myc-tagged proteins, cDNAs of human p21 and p27 were cloned into pCS3-MT (Hallier et al. 1998), and the C. elegans $c d t-2$ cDNA was cloned into pcDNA3.1/Myc-His (Invitrogen). The expression constructs pcDNA3/FlagSkp2 (Bashir et al. 2004), pCMV/HA-UB (Furukawa et al. 2005), p3XFlag-CMV10/Hs Cdt2 (Higa et al. 2006b), pCS2/p21 (Sheaff et al. 2000), and pGLUE-hDDB1 (Angers et al. 2006) were gifts from M. Pagano, Y. Xiong, H. Zhang, B. Clurman, and S. Angers, respectively. The PIP-box in p21 was mutated by overlapping PCR mutagenesis (Mikaelian and Sergeant 1992) to convert the PIP-box sequence (QTSMTDFY) to eight alanine residues.

\section{Mammalian cell culture}

HeLa and HEK293T cells were grown in Dulbecco's modified Eagle's medium (DMEM) supplemented with $10 \%$ fetal bovine serum (GIBCO-BRL). For expression in HeLa and HEK293T cells, expression constructs were transfected using Lipofectamine 2000 (Invitrogen) according to the manufacturer's instructions. Flag-Cdt2 and wild-type p21 were expressed in an HEK293T cell line stably expressing TAP-DDB1. To isolate HEK293T cell lines stably expressing TAP-DDB1, cells were transfected with pGLUE-hDDB1, and selected in a medium containing $0.7 \mu \mathrm{g} / \mathrm{mL}$ puromycine (Sigma). For the study of p21 protein turnover, HeLa cells were treated with GFP or Cdt2 siRNA and then incubated with $2.5 \mathrm{mM} \mathrm{HU}$ (Sigma) for $19 \mathrm{~h}$, and with the proteasome inhibitor MG132 (Sigma) for the last 7 $\mathrm{h}$ of the HU incubation. At time 0, HU and MG132 were removed from the culture media, and $25 \mu \mathrm{g} / \mathrm{mL}$ cycloheximide (Sigma) was added. For the analysis of p21 levels upon cell cycle entry, HeLa cells were serum-starved for $54 \mathrm{~h}$ by incubation in DMEM containing $0.02 \%$ fetal calf serum (FCS) in order to induce G0 entry. Cells were transfected with GFP or Cdt2 siRNA for the last $18 \mathrm{~h}$ of the serum starvation. At time 0 , cells were stimulated with $15 \%$ FCS plus a second siRNA transfection. At set time points, cells were harvested for Western blot analysis.

\section{Antibodies, immunofluorescence, and immunoprecipitation}

For Western blots, whole-cell lysates were prepared by treating with NP-40 buffer: $1 \%$ or $0.5 \%$ NP- $40,0.15 \mathrm{M} \mathrm{NaCl}, 10 \mathrm{mM}$ Sodium phosphate $(\mathrm{pH} 7.5), 10 \%$ glycerol, Protease Inhibitor Cocktail (Roche), 2 mM DTT, 1 mM EDTA, and 15 $\mu$ M MG132.
Monoclonal antibodies used were anti-p21 (Upstate Biotechnologies), anti-Cdc6 (DCS-180, Upstate Biotechnologies), antiMyc (9E10, Covance), anti-Flag (M2, Sigma), anti-Cyclin A (Ab6, Thermo Scientific), anti-Cyclin B1 (GNS1, Santa Cruz Biotechnologies), and anti- $\alpha$-tubulin (DM1A, Sigma). Rabbit polyclonal antibodies used were anti-Cdt2 (Bethyl Laboratories), anti-Skp2 (H-435, Santa Cruz Biotechnologies), anti-p27 (Upstate Biotechnologies), anti-p57 (Upstate Biotechnologies), anti-Cyclin A (H-432, Santa Cruz Biotechnologies), anti-CUL4 (H-66, Santa Cruz Biotechnologies), anti-PCNA (PC10, Santa Cruz Biotechnologies), and anti-HA (ab9110, Abcam). For immunofluorescence, HeLa cells were fixed in $4.0 \%$ paraformaldehyde in PBS for $10 \mathrm{~min}$ at room temperature, washed twice with $0.4 \%$ Triton $\mathrm{X}-100$ in PBS, and stained with monoclonal anti-Cdc6 (1:100) and rabbit polyclonal anti-Cyclin A (1:250). Anti-mouse Alexa-Fluor 488 (Molecular Probes) and anti-rabbit Alexa-Fluor 546 (Molecular Probes) were used as secondary antibodies. Alternatively, cells were stained with monoclonal anti-Cdc6 (1:100) and monoclonal anti-Cyclin A (1:40) using the Zenon Mouse Tricolor IgG1 labeling kit (Invitrogen). DNA was stained with $1 \mu \mathrm{g} / \mathrm{mL}$ Hoechst 33258 dye (Sigma). Immunofluorescence images were taken with the same exposure times and the images were processed identically using Adobe Photoshop software. Quantitation of nuclear and total immunofluorescence signal was performed with OpenLab software (version 5.0; Improvision). For the quantitation of Cdc6 localization in Figure 7B, 21-23 cells were analyzed for each condition.

Immunoprecipitation using anti-Myc and anti-Flag antibodies was performed as described (Kim and Kipreos 2007b). The purification of TAP-tagged DDB1 with associated proteins was modified from Angers et al. (2006). Briefly, HEK293T cells stably expressing TAP-DDB1 were cultured in a six-well plate and transfected using Lipofectamine 2000. After an 8-h incubation at $37^{\circ} \mathrm{C}$, cells were treated with $2.5 \mathrm{mM} \mathrm{HU}$ and $10 \mu \mathrm{M}$ MG132, and then harvested after an additional $10 \mathrm{~h}$ of incubation at $37^{\circ} \mathrm{C}$. Whole-cell lysates were prepared with NP-40 buffer. Cell extracts were incubated at $4^{\circ} \mathrm{C}$ with $20 \mu \mathrm{L}$ of packed streptavidin resin (Amersham); the resin was washed, and associated proteins were analyzed by Western blot using the ECL Advance chemiluminescence kit (Amersham). The immunoprecipitation of Flag-Cdt2 shown in Figure 5D was performed from a chromatin fraction of HeLa cells, prepared essentially as in Sarcinella et al. (2007), except that micrococcal nuclease (Sigma) treatment of nuclei was for $2 \mathrm{~min}$ at $37^{\circ} \mathrm{C}$, and the nuclear extract was further prepared by osmotic lysis of nuclei. Determining the intensity of Western blot protein bands was performed with unsaturated images, and involved subtracting the mean background signal and standardizing to the level of $\alpha$ tubulin in the same sample.

\section{SiRNA and cell cycle analysis}

The following ON-TARGETplus siRNAs were generated by Dharmacon (overhanging bases are in lowercase): siGFP, GCUGACCCUGAAGUUCAUCUGdTdT; siCdt2(\#2), GAAU UAUACUGCUUAUCGAuu; siCdt2(\#3), GCGCUUGAAUAGA GGCUUAuu; siCdt2(\#4), GUCAAGACCUGGCCUAGUAuu; siCdt2(\#5), ACUCCUACGUUCUCUAUUAuu; siSkp2(\#1), GC AUGUACAGGUGGCUGUUuu; siSkp2(\#2), UGUCAAUACU CUCGCAAAAuu; siSkp2(\#3), UCGGUGCUAUGAUAUAA UAuu; siSkp2(\#4), GGUAUCGCCUAGCGUCUGAuu; siSkp2(\#5), GGAUGUGACUGGUCGGUUGuu; sip21(\#1), CUUCGACUU UGUCACCGAGuu; sip21(\#2), AGACCAGCAUGACAGAUU Uuu; sip21(\#3), CGACUGUGAUGCGCUAAUGuu; sip21(\#4), CCUAAUCCGCCCACAGGAAuu; and sip21(\#5), CGUCAG AACCCAUGCGGCAuu. The Cdt2(\#1) siRNA, CAAUGGACA 
CCAGAACUCUACCUUUdTdT, was generated by Invitrogen. ON-TARGETplus SMARTpools of siRNAs (comprised of individual siRNAs \#2-\#5) were used for Cdt2, Skp2, and p21 knockdowns in all experiments except Figure 3E, which used individual Cdt2(\#1) siRNA. Both pooled and individual siRNAs were used for the experiments in Figures. 3B, 6, and 7A, for which the individual siRNAs gave results that were similar to the pooled siRNAs. siRNA SMARTpools were transfected once at $100 \mathrm{nM}$ (individual siRNAs in each pool were at $25 \mathrm{nM}$ ), and individual (nonpool) siRNAs were transfected two or three times sequentially at $100 \mathrm{nM}$. siRNAs were transfected with Oligofectamine (Invitrogen) according to the manufacturer's instructions. HeLa cells were analyzed $60 \mathrm{~h}$ after transfection. For flow cytometry to determine DNA content, HeLa cells were fixed with $70 \%$ ethanol and stained with $0.5 \mathrm{mg} / \mathrm{mL}$ propidium iodide and $20 \mu \mathrm{g} / \mathrm{mL}$ RNAse A (Sigma). Propidium iodidestained cells were analyzed using a FACSCalibur flow cytometer (Beckton-Dickinson), and the cell cycle phase distributions were determined with ModFit software (Verity).

\section{Ubiquitylation assays}

In vivo and in vitro ubiquitylation assays were performed essentially as described (Starostina et al. 2007). For in vivo ubiquitylation assays, Flag-Cdt2 and Flag-Skp2, or C. elegans MycCDT-2 and Flag-CKI-1, were coexpressed in HeLa cells (six-well plates) with HA-ubiquitin for $18 \mathrm{~h}$. To prevent premature degradation of endogenous p21, HeLa cells were treated with $10 \mu \mathrm{m}$ MG132 $8 \mathrm{~h}$ after plasmid transfection, and then harvested $10 \mathrm{~h}$ after MG132 treatment. Lysates were prepared by boiling cells with $1 \%$ SDS, then diluted 10 -fold with buffer composed of 50 $\mathrm{mM}$ Tris- $\mathrm{HCl}$ (pH 7.5), $150 \mathrm{mM} \mathrm{NaCl}, 0.1 \%$ NP-40, 1 mM DTT, $1 \mathrm{mM}$ EDTA, Protease Inhibitor Cocktail, $50 \mu \mathrm{M} \mathrm{LLnL}, 10 \mathrm{mM}$ $\mathrm{N}$-ethyl maleimide (Sigma), and $10 \mathrm{mM}$ iodoacetimide (Sigma). Endogenous p21 or Flag-CKI-1 was immunoprecipitated with anti-p21 or anti-Flag monoclonal antibodies, respectively, and analyzed by Western blot with anti-HA antibody for HA-ubiquitin detection or with either anti-p21 or anti-Flag antibodies. The in vivo ubiquitylation reaction of Figure 5E, which involved coexpressing Flag-Cdt2 and nontagged wild-type or PIPbox mutant $\mathrm{p} 21$, was performed as above, except the immunoprecipitation was from a nuclear fraction that was isolated by washing cells with buffer A (20 mM HEPES at pH 7.8; $10 \mathrm{mM}$ $\mathrm{KCl}, 1.5 \mathrm{mM} \mathrm{MgCl}_{2}, 0.34 \mathrm{M}$ sucrose, $10 \%$ glycerol, $1 \mathrm{mM} \mathrm{DTT}$, $1 \mathrm{mM}$ EDTA) (Sarcinella et al. 2007), and then incubating cells for $5 \mathrm{~min}$ in $4^{\circ} \mathrm{C}$ buffer A containing $0.2 \%$ Triton X-100, Protease Inhibitor Cocktail, $50 \mu \mathrm{M}$ LLnL, $10 \mathrm{mM} \mathrm{N}$-ethyl maleimide, $10 \mathrm{mM}$ iodoacetimide, $15 \mu \mathrm{M}$ MG132, and $50 \mu \mathrm{M}$ LLnL. After removing supernatant by low-speed centrifugation, nuclei were washed in the same buffer without Triton X-100, then boiled with $1 \%$ SDS in preparation for immunoprecipitation.

For in vitro ubiquitylation assays, 3 FFlag-Cdt2 and p2 1 were coexpressed in HEK293T cells for $48 \mathrm{~h}$. Eight hours before harvesting, $10 \mu \mathrm{M}$ of MG132 and $2.5 \mathrm{mM}$ HU were added to the cell culture. Cells were lysed with NP-40 Buffer supplemented with $1 \mathrm{mM} \mathrm{Na}_{3} \mathrm{VO}_{4}, 100 \mu \mathrm{g} / \mathrm{mL}$ of DNase I (Roche), and $10 \mathrm{mM}$ $\mathrm{MgCl}_{2}$. Flag-Cdt2 was immunoprecipitated from cell lysates with anti-Flag antibody in the presence of $10 \mathrm{mM}$ EDTA and 2.5 $\mathrm{mM}$ o-phenanthroline. To each precipitated Flag-Cdt2 immunocomplex, $20 \mu \mathrm{L}$ of ubiquitylation reaction mix was added,

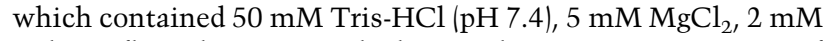
sodium fluoride, $10 \mathrm{nM}$ okadaic acid, $2 \mathrm{mM}$ ATP, $0.6 \mu \mathrm{L}$ of energy regeneration solution (Biomol Int., LP), 0.6 mM DTT, 1 $\mu \mathrm{g}$ HA-ubiquitin (Boston Biochem), 100 ng E1 (Biomol International, LP), 400 ng E2-UbcH5a, 200 ng UbcH3 (Biomol International, LP), $2 \mu \mathrm{M}$ ubiquitin aldehyde (Biomol International, LP), and $15 \mu \mathrm{M}$ MG132. Reactions were incubated for $90 \mathrm{~min}$ at $30^{\circ} \mathrm{C}$ and terminated by boiling with $1 \%$ SDS. p 21 was secondarily immunoprecipitated and analyzed by Western blot.

\section{Acknowledgments}

We are grateful to S. Angers, B.E. Clurman, J. Jin, M. Pagano, Y. Xiong, and H. Zhang for reagents; J.G. Nelson and the UGA Flow Cytometry facility for DNA content analysis; the Caenorhabditis Genetics Center for strains; and members of the Kipreos laboratory for critical reading of the manuscript. This work was supported by grants from the NIH National Institute of General Medical Sciences (NIGMS) (R01GM055297 and R01GM074212) to E.T.K.

\section{References}

Amador, V., Ge, S., Santamaria, P.G., Guardavaccaro, D., and Pagano, M. 2007. APC/C(Cdc20) controls the ubiquitin-mediated degradation of $\mathrm{p} 21$ in prometaphase. Mol. Cell 27: 462-473.

Angers, S., Li, T., Yi, X., MacCoss, M.J., Moon, R.T., and Zheng, N. 2006. Molecular architecture and assembly of the DDB1-CUL4A ubiquitin ligase machinery. Nature 443: 590-593.

Arias, E.E. and Walter, J.C. 2005. Replication-dependent destruction of Cdt1 limits DNA replication to a single round per cell cycle in Xenopus egg extracts. Genes \& Dev. 19: $114-126$.

Arias, E.E. and Walter, J.C. 2006. PCNA functions as a molecular platform to trigger Cdt1 destruction and prevent re-replication. Nat. Cell Biol. 8: 84-90.

Arias, E.E. and Walter, J.C. 2007. Strength in numbers: Preventing rereplication via multiple mechanisms in eukaryotic cells. Genes \& Dev. 21: 497-518.

Aspock, G., Kagoshima, H., Niklaus, G., and Burglin, T.R. 1999. Caenorhabditis elegans has scores of hedgehog-related genes: Sequence and expression analysis. Genome Res. 9: 909-923.

Ausubel, F.M., Brent, R., Kingston, R.E., Moore, D.D., Seidman, J.G., Smith, J.A., and Struhl, K., eds. 1994. Saccharomyces cerevisiae. In Current protocols in molecular biology, pp. 13.0.1-13.14.17. Wiley, New York.

Bashir, T., Dorrello, N.V., Amador, V., Guardavaccaro, D., and Pagano, M. 2004. Control of the SCF(Skp2-Cks1) ubiquitin ligase by the APC $/ \mathrm{C}(\mathrm{Cdh} 1)$ ubiquitin ligase. Nature 428: 190-193.

Besson, A., Dowdy, S.F., and Roberts, J.M. 2008. CDK inhibitors: Cell cycle regulators and beyond. Dev. Cell 14: 159169.

Bornstein, G., Bloom, J., Sitry-Shevah, D., Nakayama, K., Pagano, M., and Hershko, A. 2003. Role of the SCFSkp2 ubiquitin ligase in the degradation of p21Cip1 in S phase. J. Biol. Chem. 278: 25752-25757.

Bosu, D.R. and Kipreos, E.T. 2008. Cullin-RING ubiquitin ligases: Global regulation and activation cycles. Cell Div. 3: 7. doi: 10.1186/1747-1028-3-7.

Carrano, A.C., Eytan, E., Hershko, A., and Pagano, M. 1999. SKP2 is required for ubiquitin-mediated degradation of the CDK inhibitor p27. Nat. Cell Biol. 1: 193-199.

Cazzalini, O., Perucca, P., Savio, M., Necchi, D., Bianchi, L., Stivala, L.A., Ducommun, B., Scovassi, A.I., and Prosperi, E. 2008. Interaction of $\mathrm{p} 21$ (CDKN1A) with PCNA regulates the histone acetyltransferase activity of p300 in nucleotide ex- 
cision repair. Nucleic Acids Res. 36: 1713-1722.

Dulic, V., Stein, G.H., Far, D.F., and Reed, S.I. 1998. Nuclear accumulation of p21Cip1 at the onset of mitosis: A role at the G2/M-phase transition. Mol. Cell. Biol. 18: 546-557.

Furukawa, M., Andrews, P.S., and Xiong, Y. 2005. Assays for RING family ubiquitin ligases. Methods Mol. Biol. 301: 3746.

Giniger, E., Varnum, S.M., and Ptashne, M. 1985. Specific DNA binding of GAL4, a positive regulatory protein of yeast. Cell 40: $767-774$.

Hallier, M., Lerga, A., Barnache, S., Tavitian, A., and MoreauGachelin, F. 1998. The transcription factor Spi-1/PU.1 interacts with the potential splicing factor TLS. J. Biol. Chem. 273: 4838-4842.

He, Y.J., McCall, C.M., Hu, J., Zeng, Y., and Xiong, Y. 2006. DDB1 functions as a linker to recruit receptor WD40 proteins to CUL4-ROC1 ubiquitin ligases. Genes \& Dev. 20: 2949-2954.

Higa, L.A. and Zhang, H. 2007. Stealing the spotlight: CUL4DDB1 ubiquitin ligase docks WD40-repeat proteins to destroy. Cell Div. 2: 5. doi: 10.1186/1747-1028-2-5.

Higa, L.A., Banks, D., Wu, M., Kobayashi, R., Sun, H., and Zhang, H. 2006a. L2DTL/CDT2 interacts with the CUL4/ DDB1 complex and PCNA and regulates CDT1 proteolysis in response to DNA damage. Cell Cycle 5: 1675-1680.

Higa, L.A., Wu, M., Ye, T., Kobayashi, R., Sun, H., and Zhang, H. 2006b. CUL4-DDB1 ubiquitin ligase interacts with multiple WD40-repeat proteins and regulates histone methylation. Nat. Cell Biol. 8: 1277-1283.

$\mathrm{Hu}$, J. and Xiong, Y. 2006. An evolutionarily conserved function of proliferating cell nuclear antigen for Cdt 1 degradation by the Cul4-Ddb1 ubiquitin ligase in response to DNA damage. J. Biol. Chem. 281: 3753-3756.

James, P., Halladay, J., and Craig, E.A. 1996. Genomic libraries and a host strain designed for highly efficient two-hybrid selection in yeast. Genetics 144: 1425-1436.

Jin, Y., Lee, H., Zeng, S.X., Dai, M.S., and Lu, H. 2003. MDM2 promotes $\mathrm{p} 21 \mathrm{waf} 1 / \mathrm{cip} 1$ proteasomal turnover independently of ubiquitylation. EMBO J. 22: 6365-6377.

Jin, J., Arias, E.E., Chen, J., Harper, J.W., and Walter, J.C. 2006. A family of diverse Cul4-Ddb1-interacting proteins includes Cdt2, which is required for S phase destruction of the replication factor Cdt1. Mol. Cell 23: 709-721.

Jin, Y., Zeng, S.X., Sun, X.X., Lee, H., Blattner, C., Xiao, Z., and $\mathrm{Lu}, \mathrm{H}$. 2008. MDMX promotes proteasomal turnover of $\mathrm{p} 21$ at G1 and early $S$ phases independently of, but in cooperation with, MDM2. Mol. Cell. Biol. 28: 1218-1229.

Kamath, R.S., Martinez-Campos, M., Zipperlen, P., Fraser, A.G., and Ahringer, J. 2001. Effectiveness of specific RNAmediated interference through ingested double-stranded RNA in Caenorhabditis elegans. Genome Biol. 2: RESEARCH0002.1- RESEARCH0002.10. doi: 10.1186/gb-20002-1-research0002.

Kamura, T., Hara, T., Kotoshiba, S., Yada, M., Ishida, N., Imaki, H., Hatakeyama, S., Nakayama, K., and Nakayama, K.I. 2003. Degradation of p57Kip2 mediated by SCFSkp2-dependent ubiquitylation. Proc. Natl. Acad. Sci. 100: 1023110236.

Kim, Y. and Kipreos, E.T. 2007a. Cdt1 degradation to prevent DNA re-replication: Conserved and non-conserved pathways. Cell Div. 2: 18. doi: 10.1186/1747-1028-2-18.

Kim, Y. and Kipreos, E.T. 2007b. The Caenorhabditis elegans replication licensing factor CDT-1 is targeted for degradation by the CUL-4/DDB-1 complex. Mol. Cell. Biol. 27: 13941406

Kim, J. and Kipreos, E.T. 2008. Control of the Cdc6 replication licensing factor in metazoa: The role of nuclear export and the CUL4 ubiquitin ligase. Cell Cycle 7: 146-150.

Kim, J., Feng, H., and Kipreos, E.T. 2007. C. elegans CUL-4 prevents rereplication by promoting the nuclear export of CDC-6 via a CKI-1-dependent pathway. Curr. Biol. 17: 966972.

Lee, J. and Zhou, P. 2007. DCAFs, the missing link of the CUL4-DDB1 ubiquitin ligase. Mol. Cell 26: 775-780.

Li, A. and Blow, J.J. 2005. Cdt1 downregulation by proteolysis and geminin inhibition prevents DNA re-replication in Xenopus. EMBO J. 24: 395-404.

Licitra, E.J. and Liu, J.O. 1996. A three-hybrid system for detecting small ligand-protein receptor interactions. Proc. Natl. Acad. Sci. 93: 12817-12821.

Machida, Y.J. and Dutta, A. 2007. The APC/C inhibitor, Emil is essential for prevention of rereplication. Genes \& Dev. 21: 184-194.

Masih, P.J., Kunnev, D., and Melendy, T. 2008. Mismatch Repair proteins are recruited to replicating DNA through interaction with proliferating cell nuclear antigen (PCNA). Nucleic Acids Res. 36: 67-75.

Melixetian, M., Ballabeni, A., Masiero, L., Gasparini, P., Zamponi, R., Bartek, J., Lukas, J., and Helin, K. 2004. Loss of Geminin induces rereplication in the presence of functional p53. I. Cell Biol. 165: 473-482.

Mikaelian, I. and Sergeant, A. 1992. A general and fast method to generate multiple site directed mutations. Nucleic Acids Res. 20: 376.

Moldovan, G.L., Pfander, B., and Jentsch, S. 2007. PCNA, the maestro of the replication fork. Cell 129: 665-679.

Nishitani, H., Sugimoto, N., Roukos, V., Nakanishi, Y., Saijo, M., Obuse, C., Tsurimoto, T., Nakayama, K.I., Nakayama, K., Fujita, M., et al. 2006. Two E3 ubiquitin ligases, SCFSkp2 and DDB1-Cu14, target human Cdt1 for proteolysis. EMBO I. 25: 1126-1136.

Nguyen, V.Q., Co, C., and Li, J.J. 2001. Cyclin-dependent kinases prevent DNA re-replication through multiple mechanisms. Nature 411: 1068-1073.

Pines, J. and Hunter, T. 1992. Cyclins A and B1 in the human cell cycle. Ciba Found. Symp. 170: 187-196.

Ralph, E., Boye, E., and Kearsey, S.E. 2006. DNA damage induces Cdt1 proteolysis in fission yeast through a pathway dependent on Cdt2 and Ddb1. EMBO Rep. 7: 11341139.

Sansam, C.L., Shepard, J.L., Lai, K., Ianari, A., Danielian, P.S., Amsterdam, A., Hopkins, N., and Lees, J.A. 2006. DTL/ CDT2 is essential for both CDT1 regulation and the early G2/M checkpoint. Genes \& Dev. 20: 3117-3129.

Sarcinella, E., Zuzarte, P.C., Lau, P.N., Draker, R., and Cheung, P. 2007. Monoubiquitylation of H2A.Z distinguishes its association with euchromatin or facultative heterochromatin. Mol. Cell. Biol. 27: 6457-6468.

Senga, T., Sivaprasad, U., Zhu, W., Park, J.H., Arias, E.E., Walter, J.C., and Dutta, A. 2006. PCNA is a cofactor for Cdt1 degradation by CUL4/DDB1-mediated N-terminal ubiquitination. J. Biol. Chem. 281: 6246-6252.

Sheaff, R.J., Singer, J.D., Swanger, J., Smitherman, M., Roberts, J.M., and Clurman, B.E. 2000. Proteasomal turnover of p21Cip1 does not require p21Cip1 ubiquitination. Mol. Cell 5: 403-410.

Starostina, N.G., Lim, J.M., Schvarzstein, M., Wells, L., Spence, A.M., and Kipreos, E.T. 2007. A CUL-2 ubiquitin ligase containing three FEM proteins degrades TRA-1 to regulate $C$. elegans sex determination. Dev. Cell 13: 127-139.

Sutterluty, H., Chatelain, E., Marti, A., Wirbelauer, C., Senften, M., Muller, U., and Krek, W. 1999. p45SKP2 promotes 
p27Kip1 degradation and induces S phase in quiescent cells. Nat. Cell Biol. 1: 207-214.

Tsvetkov, L.M., Yeh, K.H., Lee, S.J., Sun, H., and Zhang, H. 1999. p27(Kip1) ubiquitination and degradation is regulated by the SCF(Skp2) complex through phosphorylated Thr187 in p27. Curr. Biol. 9: 661-664.

Vaziri, C., Saxena, S., Jeon, Y., Lee, C., Murata, K., Machida, Y., Wagle, N., Hwang, D.S., and Dutta, A. 2003. A p53-dependent checkpoint pathway prevents rereplication. Mol. Cell 11: 997-1008.

Waga, S., Hannon, G.J., Beach, D., and Stillman, B. 1994. The p21 inhibitor of cyclin-dependent kinases controls DNA replication by interaction with PCNA. Nature 369: 574-578.

Yoshida, K., Takisawa, H., and Kubota, Y. 2005. Intrinsic nuclear import activity of geminin is essential to prevent re-initiation of DNA replication in Xenopus eggs. Genes Cells 10: 63-73.

Yu, Z.K., Gervais, J.L., and Zhang, H. 1998. Human CUL-1 associates with the SKP1/SKP2 complex and regulates p21(CIP1/WAF1) and cyclin D proteins. Proc. Nat1. Acad. Sci. 95: 11324-11329.

Zhong, W., Feng, H., Santiago, F.E., and Kipreos, E.T. 2003. CUL-4 ubiquitin ligase maintains genome stability by restraining DNA-replication licensing. Nature 423: 885-889.

Zhu, W., Chen, Y., and Dutta, A. 2004. Rereplication by depletion of geminin is seen regardless of p53 status and activates a G2/M checkpoint. Mol. Cell. Biol. 24: 7140-7150. 


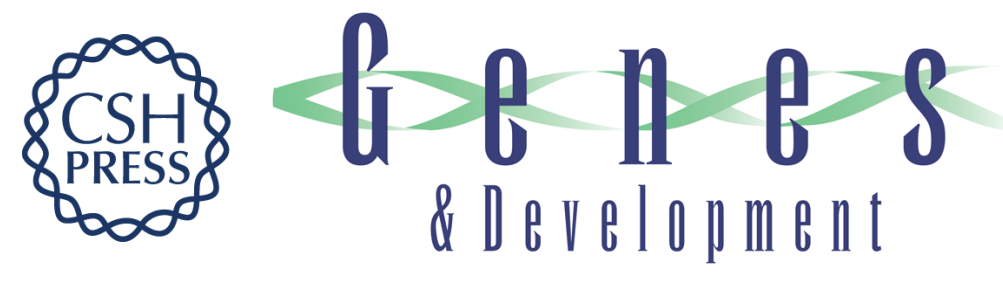

\section{The CRL4Cdt2 ubiquitin ligase targets the degradation of p21 Cip1 to control replication licensing}

Youngjo Kim, Natalia G. Starostina and Edward T. Kipreos

Genes Dev. 2008, 22:

Access the most recent version at doi:10.1101/gad.1703708

References This article cites 56 articles, 21 of which can be accessed free at: http://genesdev.cshlp.org/content/22/18/2507.full.html\#ref-list-1

License

Email Alerting

Receive free email alerts when new articles cite this article - sign up in the box at the top Service right corner of the article or click here.

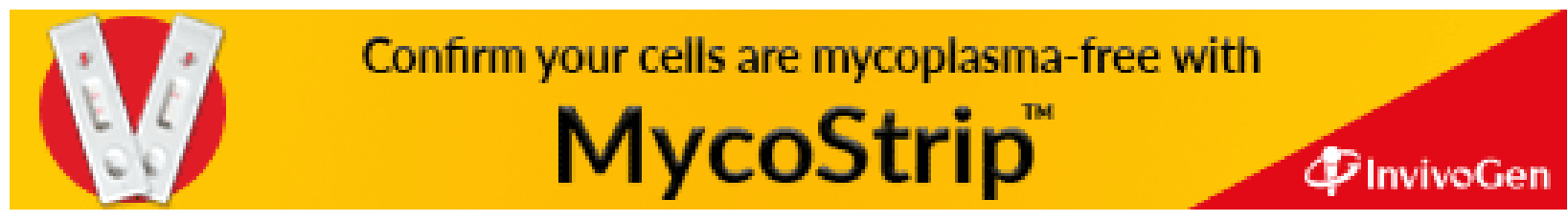

